\title{
EFFECTIVENESS OF QUALITY OF CHIEF INTEGRITY OFFICER, ETHICAL CLIMATE ON THE LEVEL OF ETHICS AND INTEGRITY IN THE MALAYSIAN FEDERAL
}

\author{
Asmawati Sajari1, , Hasnah Haron ${ }^{1}$, Ishak Ismail11 \\ ${ }^{1}$ Faculty of Industrial Management, Universiti Malaysia Pahang, Pahang, Malaysia
}

ABSTRACT - The purpose of this quantitative study is to examine the relationship between level of ethics and integrity with Quality of Chief Integrity Officer (independence, competence, work performance) and ethical climate in the Malaysian public-sector organizations. Out of 128 questionnaires that was emailed to $\mathrm{CIO}$ s in the Federal level, 83 questionnaires were received and usable. The results of this study showed that the Quality of $\mathrm{ClO}$ (competence, work performance) and ethical climate is significantly related to the level of ethics and integrity of the public sector in Malaysia. $\mathrm{ClO}$ need to perform their roles such as coordinating and monitoring programs and report any breaches of integrity without fear and favour. To nurture a good ethical climate in the organization, clear policies, guideline and code of conduct should be established in all government ministries, department and statutory body in the public sector. Non-ethical conduct should be reprimanded, good ethical behavior should be rewarded accordingly and should be evident to all in the organization. The overall score of level of ethics and integrity is $79.30 \%$, which shows that the Malaysian public sector is at "seeing ethics and integrity systematically and having a robust approach".

ARTICLE HISTORY

Received: 12-08-2019

Accepted: 04-12-2019

\section{KEYWORDS}

Chief Integrity Officer; work performance; competence; independence; ethical climate; ethics; integrity; public sector

\section{INTRODUCTION}

The success of implementing ethics and integrity in the public sector will reduce the ethical scandals such as corruption, bribery, fraud, governance inefficiency, misappropriation of assets, poor internal control, unethical behavior and avoiding an adverse effect on government and economy in the future. Thus, ethics and integrity have to be translated into good governance and efficient services delivery by government agencies to prevent issues of integrity in the public sector. In addition, ethics and integrity are two of the key mechanisms of good corporate governance and have become benchmarks for assessing the development of the nation. Without good corporate governance, no reasonable sustainability can be achieved from the part of the country inhabitants and the country itself (Ali, 2015). Thus, case study from Mass Rapid Transit (MRT) committee has been stated that good governance can completion of the large project ahead of schedule at lower cost than original estimate budget (Malaymail, 2017). This is one of the steps to increase towards the level of ethics and integrity in the public sector Malaysia organization.

There are several ways to determine the level of ethics and integrity in the public sector. Such as the Public Integrity Index established by Global Integrity is to help control or reduced current corruption, prevent abuse of power and promote more effective of good governance (Camerer, 2006). In addition, there is a comprehensive strategy study to enhance the integrity, especially in combating corruption. Among them are studies done by international institutions such as Organizations for Economic Cooperation and Development (OECD). Transparency International (Corruption Perception Index), and Global Integrity (Global Integrity Report). At the national level, there are studies the conducted by Malaysian Institute of Integrity (MII), Malaysian Anti-Corruption Commission (MACC), Public Complaints Bureau with using Corporate Integrity Assessment Questionnaire (CIAQ) to determine level of ethics and integrity in the organization (Siddique. 2010).

The government acknowledged that ethics and integrity in the public sector are important as it is needed to manage and administer an organization and contributes to better deliver services and national development. Therefore, the Integrity Unit to establish in each of the government departments, ministry and statutory body which lead by the Chief Integrity Officer so that implementation of integrity is more effective in handle unethical issues in the organization. Table 1.1 shows the initiatives undertaken by the Malaysian government to enhance ethics and integrity in the Malaysian public sector. Amongst the initiatives include the appointment of the Chief Integrity Officer (CIO) and the implementation of the Certified Integrity Officer (CeIO) programme by the Malaysia Anti-Corruption Academy (MACA). 
Table 1: Initiatives taken by Malaysia Government to Promote Ethics and Integrity in the Malaysian Public Sector

\begin{tabular}{|c|c|}
\hline Year & Milestone \\
\hline 1950 & Prevention of Corruption Ordinance \\
\hline 1961 & Prevention of Corruption Act \\
\hline 1967 & Anti-Corruption Agency (ACA) - Anti-Corruption Act 1967 \\
\hline 1980 & Introduced "Clean, Efficient, Trustworthy" \\
\hline \multirow[t]{2}{*}{2004} & Establishment of the Malaysian Institute of Integrity (MII) \\
\hline & Launching of the National Integrity Plan (NIP) \\
\hline 2006 & Establishment of the Malaysia Anti-Corruption Academy ((MACA) \\
\hline 2008 & $\begin{array}{l}\text { Establishment of the Corporate Integrity Development Center (CIDC) } \\
\text { * Putting the Chief Integrity Officer (CIO) from ACA “Kader" at ministries, departments, agencies } \\
\text { in high risk unethical scandal. }\end{array}$ \\
\hline \multirow[t]{3}{*}{2009} & $\begin{array}{l}\text { Transformed: Anti-Corruption Agency (ACA) to Malaysia Anti-Corruption Commission } \\
\text { (MACC's) - MACC Act } 2009\end{array}$ \\
\hline & Implementation of the Certified Integrity Officer (CeIO) Programme \\
\hline & Establishment of Committee on Integrity (CIG) \\
\hline 2013 & Established of the Agency Integrity Management Division (AIMD) \\
\hline 2014 & $\begin{array}{l}\text { Establishment of Integrity and Governance Committee - Chief Integrity Officer (CIO) have a } \\
\text { certificate of integrity officer as its Head Integrity Unit }\end{array}$ \\
\hline $\begin{array}{l}2019- \\
2023\end{array}$ & National Anti-Corruption Plan (NACP) \\
\hline
\end{tabular}

In the public sector, ethical behavior and integrity are important functions in ensuring accountability and transparency. Thus, the Malaysian government has implemented ethics and integrity initiatives even before it gained independence in 1957. In 1950 for example, a commission report on the "Integrity of the Public Services" focusing on corruption offenders was shaped following the enactment of the Corruption Prevention Ordinance 1950 (UKM, 2007). The Corruption Prevention Act 1961 later ensued. In addition, 1967, the Anti-Corruption Agency was established to eliminate bribery and against the action of unethical in the public sector various departments. Malaysia has been effectively transforming the country from one that is developing into one that will be developed. Before that, the government introduced the strategy known as "Clean, Efficient and Trustworthy" in the 1980s to replace the 1950 Prevention of Corruption Ordinance and the 1961 Prevention of Corruption Agency Act with the aim of ensuring the prevention of corruption and increasing the practise of integrity in the public sector various departments (Lokman. \& Talib, 2015).

In the public sector, the government also established several control mechanisms to introduce accountability in spending to organizations. In 2004, the Malaysian Institute of Integrity (MII) was established as an initiative by the government to create a nation with a high level of integrity which would be resilient and embody the universal good value. In the same year, the National Integrity Plan (NIP) was introduced as a major effort made by government to promote a culture of integrity. MII provides a framework that would support the effective coordination and implementation of NIP. Chaired by the Chief Secretary to the government and governed by a Board of Directors, MII is responsible for monitoring and coordinating and implementation particularly devising appropriate indices to measure performance in achieving NIP targets, preparing annual reports to Malaysia Integrity system and organizing conventions of stakeholders to debate integrity issues seeking new and innovative ways to move forward (Siddique, 2010).

In 2006, Malaysian government established the Malaysia Anti-Corruption Academy (MACA) to provide trainers and experts to formulate and conduct, training, seminar and workshop in fighting corruption. In 2008, the government established the Corporate Integrity Development Centre (CIDC) that is responsible for developing course modules for the Certified Integrity Officer program. The course modules were developed with the cooperation of government agencies and government-linked company (GLCs). In August 2008, MACC placed their Chief Integrity Officers as "kader" at ministries, department and agencies governments that have a high risk of corruption. There are three levels of risk in the public sector and they are high risk, medium risk and low risk. The federal government was said to have a moderate to high risk and the state government was said to have a low risk in Circular No.6 (2003).

On 1st January 2009, ACA was transformed to become the Malaysian Anti-Corruption Commission (MACC) whose main function was to enforce the law to prevent corruption. There are three pillars of integrity which are (i) education and awareness (ii) prevention and government, and (iii) detection and consequence management (Norazlan, 2013). In 2009, the Committee on Integrity Governance (CIG) was established. The purposed of CIG is to improve the administration of the government, enhance governance, reduce bureaucratic and prevent corruption. The Certified Integrity officer programme requires a CIO to undergo a six-months training by MACA This programme expectations to be able to curb unethical issues at various levels of the organizations. The objectives of the programme are (i) promote compliance in terms of laws and regulations, system and procedure, (ii) foster zero tolerance towards fraud, corruption and abuse of power, and (iii) consults and advise the organisation's management on awareness and preventive measure (NKRA ENewsletter, 2013). This is one of efforts initiated by the government to increase ethics and integrity in public sector. Upon the recommendation by MACC in 2013, Unit Integrity was established to further enhance integrity in all federal and state government agencies. This will prevent the criminal misconduct and violations of the code of conduct and ethics in the 
civil services organization. As a Head of the Integrity Unit who has a certificate as an integrity officer, the CIO will manage and implement effective initiatives in integrity, managing complaints,

Currently, in 2019, the Malaysian government has promoted a new initiative to combat corruption which is the National Anti-Corruption Plan (NACP) and will be launched by the Prime Minister of Malaysia, Dato' Seri Dr Mahathir Mohammed. The National Anti-Corruption Plan (NACP) is an anti-corruption policy in Malaysia that reflects the people's expectations for a greater corrupt-free nation that promotes transparency, accountability and integrity culture in every Malaysians and will be replacing the National Integrity Plan. With the establishment of NACP, it is hoped that the ranking of corruption will decrease, and Malaysia will become an inspiration for other countries thus become a benchmark to combat corruption in the public sector (GIACC, 2019).

Problem Statement

This study will determine the level of ethics and integrity in the public sector. Quality of CIO and ethical climate are hypothesized to be a factor that will an influence on level of ethics and integrity. Based on the Transparency International (TI) Corruption Perception Index (CPI), there are cases of allegations of corruption in the newspapers and social media that highlighted unethical behavior and integrity as the main problem in the public sector. Even though, the Malaysian government has implemented various initiatives to reduce the occurrence of unethical scandals in the public sector, but statistics reports still show an increase every year (Siddiquee, 2010). Previous studies show that having a corporate integrity system in an organization, will lead to a good level of ethics and integrity in the workplaces. However, the research has been conducted in listed companies. Meanwhile, study of this research, would assist the government to identify the factors that would assist in nurturing and promoting the value of integrity in the government sector.

According to the Asia Pacific Fraud Survey Report Series 2013, it has been noted that the highest level of bribery and corruption is from Malaysia and China. A survey by Transparency International - Malaysia (TI-M) on Corruption Perceptions Index in the public sector, also shows the "scores" and "ranking" dropped in 2016, 2017 and 2018. Example due to drop such as 1 Malaysia Development Berhad (1MDB), SRC International Sdn. Bhd case, and Federal Land Development Authority (Felda) scandal (Theedgemarkets, 2018). This is indicating that graft-fighting measures efforts are still inadequate to fighting corruption, even though the government is on the right way to restore public confidence. Numerous steps should be taken to improve public awareness mainly towards public sector accountability (Said, Alam, $\&$ Khalid, 2015). However, the issue of corruption and unethical conduct remains critical. Table 2 shows the annual statistics on arrests up to July 2016 which comprised of 588 cases whereby 296 cases involved public sector officials.

Table 2: Annual Statistics on Arrest as of July $2016(n=588)$

\begin{tabular}{lcccccccc}
\hline Month & Jan & Feb & Mac & Apr & May & Jun & Jul & Total \\
\hline Top Management & 0 & 0 & 1 & 0 & 0 & 0 & 0 & Public \\
$\quad$ Professional and & 15 & 6 & 7 & 7 & 5 & 23 & 5 & Official \\
Management & 38 & 39 & 31 & 25 & 42 & 33 & 19 & 24 \\
$\quad$ Support Staff & 53 & 45 & 39 & 32 & 47 & 56 & 296 \\
Total & 30 & 8 & 44 & 28 & 14 & 9 & 6 & 13 \\
\hline Private Sector & 23 & 14 & 21 & 30 & 36 & 14 & Civilian \\
General Public & 0 & 0 & 0 & 0 & 0 & 0 & 0 & 0 \\
Local Councillor & 0 & 0 & 1 & 0 & 0 & 1 & & 29 \\
Politician & 53 & 22 & 66 & 58 & 50 & 24 & 19 & 292 \\
Total & & & & & & & &
\end{tabular}

Table 3 shows the percentages of fraud cases based on the different number of government agencies. Research conducted by Kamaliah, Marjuni, Mohamed, Mohd-Sanusi \& Anugerah (2018), shows that the higher percentages are fraud cases namely, misappropriate of assets, followed by theft, procurement fraud, bribes, payroll fraud and, financial statement fraud in the federal government agencies. Meanwhile, a percentage of fraud cases misappropriation of assets in local government agencies is the lowest percentage compared to the federal government agencies. Therefore, having a Chief Integrity Officer and a good ethical climate at the workplace will help to enhance ethical practices among employees and as a result will reduce misconduct in the public sector organisation.

Table 3: Percentage of fraud cases based on the type of government agencies

\begin{tabular}{lccc}
\hline Fraud & Federal $(\%)$ & Local $(\%)$ & Others $(\%)$ \\
\hline Bribery/kickbacks & 24.18 & 10.99 & 12.09 \\
Theft & 36.26 & 14.29 & 17.58 \\
Misappropriate of assets & 37.36 & 16.48 & 17.58 \\
Procurement Fraud & 35.16 & 14.29 & 15.38 \\
Payroll Fraud & 14.29 & 4.40 & 9.79 \\
Financial statement fraud & 7.69 & 0.00 & 2.20 \\
\hline
\end{tabular}

A research conducted by Accounting Research Institute (ARI, 2016) found that the government related parties request for bribe more than the others as shown in Figure 1. In this study, questionnaires were distributed to both technical and non-technical employees in both public and the private sector. The questionnaire asks the respondents to rate which party 
requests for bribe the most when dealing with business transactions with them. Findings show that the most party that request for bribe is the government official (38\%).

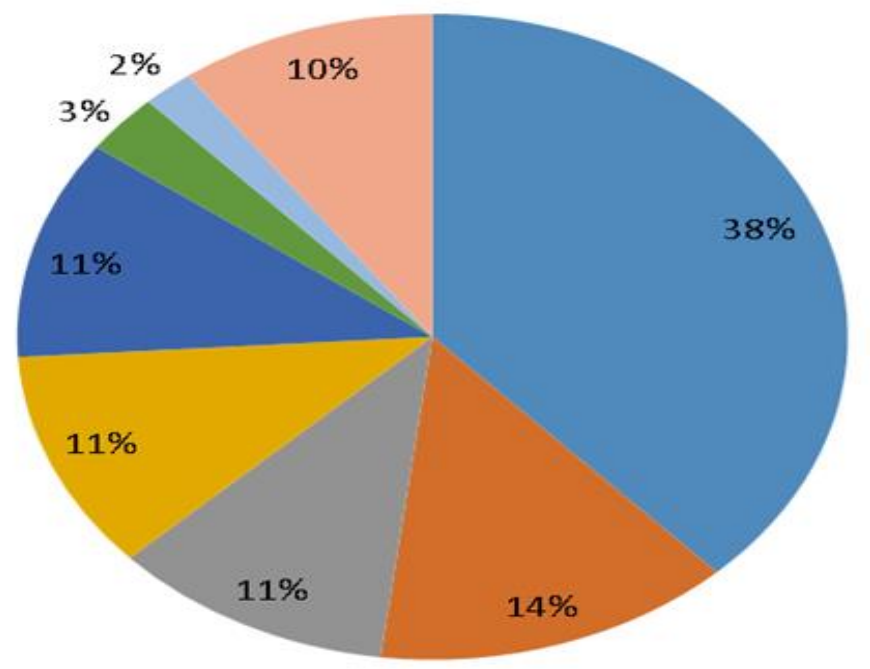

= Government Official

- Government Employee

E Police

- Member of Judiciary

- Ruling Party Official

- Private Company

Representative

- NGO Representative

- Other

Figure 1: Who Requested the Bribe?

Source: Accounting Research Institute (2016)

Thus, Prime Minister Directive No. 1 of 2009 has taken a vital step to encourage further on integrity. This directive is a mandate establishment of a committee on integrity governance in all government ministry and departments. The Certified Integrity Officer (CeIO) is an accredited officer that plays an integral role within an organization to inculcate integrity and ethical values. A prepared CeIO would have a decent comprehension of Integrity Management, the required Legal Framework and Compliance and Monitoring System just as the capacity to build up an Integrity Action Plan. One of mechanisms to push companies to follow ethical conduct is through the appointment of an ethical and compliance officer. Similar terms used for ethical and compliance officer includes Compliance Officer (CO), Ethics and Compliance Officer (ECO), Chief Ethics and Compliance Officer (CECO) and Chief Integrity Officer (CIO). This officer is expected to guide and protect an organisation from unethical behaviour that will harm the organisation's reputation. They are also expected to formulate and review corporate integrity strategy and action plan to promote integrity and set up personnel and integrity committee at the board level. This position is one of the most important position in the company because he/she is responsible for creating and maintaining organization environments that aim to produce ethical and law-abiding employees and leaders (Treviño, den Nieuwenboer, Kreiner, \& Bishop, 2014).

Furthermore, the Malaysian Anti-Corruption Academy (MACA), through its Corporate Integrity Development Centre (CIDC) conducted a CeIO program for this purpose. All CeIOs will be awarded a certificate by MACA. This CeIO program has been implemented for more than five (5) years. In Malaysia, a CIO is a Senior Officer from MACC that acts as an advisor in their agency. This position was created to ensure that there is an improvement in the level of ethics and integrity in the public sector, as corruption and bribery is getting more serious by the day. Malaysia views this issue unethical and lack of integrity in the public sector seriously. Therefore, government has emphasized that the public sector in Malaysia needs to be effective, efficient and ingrained with the highest level of ethics and integrity. This is so that, Malaysia will be able to move towards achieving a high-income economy status in 2020. Thus, the importance of a good quality CIO and ethical climate in the organizations will help to ensure the achievement of this objective.

In this study, CIO is perceived as a person who has an important role and responsibility to ensure that ethics and integrity is implemented in the organization. However, there is no latest research conducted with the knowledge of the researcher, to evaluation the effect of CIO on the level of ethics and integrity in Malaysia's public-sector. Therefore, one of the objectives of this research is to examine this issue. The research will examine the relationship of CIOs on the level of ethics and integrity in Malaysia's public-sector organizations. If CIO's relationship is positive on the level of ethics and integrity in an organisation, then this programme would be recommended to be continued otherwise, an intervention or improvement is needed to relook at other alternatives to improve the level of ethics and integrity of an organisation. Previous research has shown that having a quality CIO (Chandler, 2015; Treviño et al., 2014) and a good ethical climate (Kolthoff, Erakovich \& Lasthuizen, 2010) will enhance the level of ethics and integrity in an organisation. Therefore, this study will examine the issue in the Malaysian context. The findings of this study may help the public sector to increase the level of ethics and integrity in their organisations and assist in preventing unethical conducts. If the problem of ethics and integrity is resolved, it will encourage investors from abroad to come and invest in this country. This will help to increase economic growth and develop Malaysia to achieve a high-income economy status in 2020.

\section{Research Objectives}

The objectives of this study are as follows:

1. To examine the level of the twelve dimensions of the level ethics and integrity in the Malaysian public sector. 
2. To examine the relationship between Quality of Chief Integrity Officer (CIO) comprising of independence, competence and work performance with the level of ethics and integrity in the Malaysian public sector.

3. To examine the relationship between ethical climate with the level of ethics and integrity in Malaysian public sector.

\section{LITERATURE REVIEW}

Previously, the Malaysian public sector known as the Malaysian Civil Service (MSC). It is divided into three tiers governments, namely, i) federal government ii) state government iii) local government (Azleen \& Nurul, 2013). The Federal Government is the Central Government with 25 Federal Ministries headed by Ministers, administrative heads and the Secretary-Generals. Meanwhile, 13 of State Governments implementing state functions with Federal Department. Also, generates own revenues and incur their own expenditures even though the Federal Government undertakes projects at the state level agreed upon in the Concurrent List and Federal List in the Constitution of Malaysia. There are federal statutory bodies and state statutory bodies. The complexity of structure requires the Malaysian government to adopt a comprehensive procedure and guidelines especially related with planning and control on the financial management matters (Ali, 2015). Malaysia is no exception towards promoting integrity and curb of corruption has become a major component of government reforms such as many countries. Economic Transformation Program (ETP) is system of Malaysia government become a high-income nation by year 2020. The Anti-Corruption Agency was established in 1967 with clear mandates, it was reformed and revitalized subsequently to make it more effective in containing corruption and all forms of mal administration in the society. Since the year 2003, fighting corruption has been steadfast in the government agenda. The variety of new initiatives and strategies have been planned and implemented ever since. In addition, Malaysia also has an elaborate anti-corruption framework. However, Malaysia presents an interesting case where the level of corruption has remained high and the plethora of strategies and recent campaigns appear to have made hardly any difference in containing and combating corruption in the society (Siddiquee, 2010).

\section{Theory}

This study applies the Hunt and Vitell Theory of Ethics (1986). This theory examines ethical dilemma and ethical decision-making on individuals arrive at the level of ethics and integrity in the organizations. Hunt and Vitell's Theory, explain that behavioural consequences impact future deliberations regarding ethical issues, presupposing that the decision-maker reaches a "right" or a "wrong" decision that informs subsequent ethical decision making (Pimental et al., 2010). Thus, personal characteristics (e.g, attitudes and knowledge) will explain the relationship between of Quality of CIO (Independence, competence, work performance) with the level of ethics and integrity. Meanwhile, organizational environment will explain the relationship between ethical climate with the level of ethics and integrity.

\section{Quality of Chief Integrity Officer (CIO)}

Despite growing research in behavioral ethics, little is known about one of the most important ethics-related roles in organizations. There are numerous names given for the ethics-related role such as Ethics and Compliance Officer (ECO) (Chandler, 2015; Treviño et al., 2014), Compliance Officer (CO) (David Chandler, 2015), Ethics Ambassador (Irwin \& Bradshaw, 2011), Ethics Officer and Chief Ethics Officer (Guten et al., 2004). In Malaysia, Chief Integrity Officer (CIO) was introduced (Circular No. 6, 2013). Prior to that, MACA had conducted specialized training programme of Certified Integrity Officer (CeIO) to prepare these CIUs for their role and responsibility. In this study, the quality of CIO (Chief Integrity Officer) will use measurement of independence, competence and work performance as factor influence the level ethics and integrity in public sector organization.

\section{Independence}

Independence is the freedom from a condition that threatens the objectivity or the presence of objectivity (IIAM, 2008). According to Qun (2013), independence for internal audit is an important characteristic that must be involved to confirm that internal audit is adequately effective. His study measures the independence based on reports for administrative report purposes, in most situations, the CAE should report straight to the chief executive officer of the organization. Administrative reporting is the reporting related in the organization's management structure that facilitates the daily procedures of the internal audit such as, human resources administration, including, budgeting, administration of the organization's policies and procedure. In the case of CIO, reporting operationally refers to reporting within the organization's management structure that facilitates the day-to- day operations of the internal activity, for example to coordinate and monitor integrity programs of the CIO that requires reporting to Head of Department. Meanwhile, reporting functionally is directly reporting to a higher level outside the organization by the CIO on issues related to the abuse of power and money laundering. Outside parties include the Agency Integrity Management Division to avoid restraining of the report by the organization. At the individual objectivity level, CIO should have an impartial, unbiased attitude and avoid conflicts of interest in conducting engagements towards level ethics and integrity in organization public sector. 


\section{Competence}

According to Thomson (1995), competence is defined as "attributes needed by an individual to perform work. An individual becomes competent through a combination of education, training and work practices. Competence has been classified to have four facets which are professional, methodological, social and self-competence (Kauffeld, 2006). Measuring professional competence addresses the skills, knowledge and all employees have to have in order to practice his or her occupation. It is also to identify potential for improvement within the company and develop relevant technical solution (Kauffeld, 2006, Heinen, 2013). Competence methodologies are the cognitive skill of an individual to learn new working methods independently or gain new expertise (Erpenbeck and Michel, 2006). These skills should be used across any setting and applied to any particular situations (Heinen, 2011: Kauffeld, 2006). Social competence involves the experience, knowledge and ability to cope with various social interaction situations (Frey and Ruppert, 2013; Kauffeld, 2006). Self-competence is the ability for self-assessment and for the independent creations of conditions in which an individual as well as their value and attitude towards their own work are developed (Frey and Ruppert, 2013, Kauffeld, 2006). Competence is one of the important characteristics to an employee and employer in an organization. It is important because this criterion will show in their work outcome whether it be good or bad in all tasks done. Individual competence can be described as a set of skills and knowledge that an individual need in order to perform a specified job effectively (Baker et al., 1997).

According to Qun (2013), definition of competence is the quality of being adequately or well qualified physically and intellectually. Meanwhile, the measurement of competence also looks at years of experience and educational qualification level. He conducted the study on competence of internal auditors based on the sum of mean educational qualification level among audit staff, which an internal auditors' average score of four will be awarded for "PhD", three for "master", two for "degree" and one for "diploma". The mean of educational qualification is the sum of the score divided by the maximum score given to the number of staffs. For experience work, based on the average of the year, the more experienced staff usually have accumulated extra knowledge and skills, therefore the score of six will be awarded for "more than 15 years", five for "12 to less than 15 years", four for "9 to less than 12 years", three for "6 to less than 9 years", two for " 3 to less than 6 years" and one for "Less than 3 years". The mean of experience is derived by dividing the sum of the score by the maximum score. Similarly, in this study, the measurement of CIO competence will be based on the educational qualification level and working experience.

\section{Work performance}

The definition of work performance is the behaviors or actions that contribute to the goals of the organization (Campbell's, 1990). There are three views of on different defining of work performance namely: (i) in terms of behavior rather than results, (ii) includes only those behaviors that are relevant to the organization's goals and (iii is multidimensional. Meanwhile, Viswesvaran and Ones (2000) defined work performance as accessible activities, behavior and results that employees engage in or bring about, that are related with and contribute to organizational goals. Besides that, the definition of work performance (IIAM, 2008) is a process of procedures that includes audit planning, performing engagement and communicating audit results. According to studies done by Qun(2013), work performance is the responsibility of internal audit to ensure achievement of objective effects and quality of work performance. This ensures that entirely planned work is a priority and that audit resources are applied in a good possible method. The IIA Performance Standard 2200 (IIAM, 2008) deals with engagement planning and states that internal auditors should develop and record a plan for each engagement, including the scope, objective, timing and resource allocations. Engagement planning involved the adequacy of the scope of work and related programs whether it is, performed by people having adequate technical training and expertise. His studies were used as a measurement of work performance in engagement planning, an accomplishment the engagement and communicating results of the engagement. In this study, work performance is defined as the role that the CIO must ensure the level of ethics and integrity of an organization. The roles are as listed in Circular Series 1 No.1 (2011) which are the CIOs' roles.

\section{Ethical Climate}

The stories of collapse companies such as Enron, Tyco, and World Com proven, that ethics and integrity are the most of important elements in governance that affect not only organizational effectiveness but also survival skills. (Bartels et al., 1998; Buller and McEvoy, 1999; Hunt et al., 1989). The ethical climate is important in the organization because one of the factors influencing the employees' perception in emphasize the ethical guideline of organizations and encourage employees' ethical work behaviour at the workplace. (Martin and Cullen, 2006; Schminke et al., 2007) as cited in the study done by Kwon Choi et al., (2013).Based on previous research, Victor and Cullen (1988) defined ethical climate as "the prevailing perceptions of distinctive organizational follows and procedures that have ethical content" or "those aspects of work climate that determine what creates ethical behaviour at work. Ethical climate can be measure with fouritem subscales which follows nine theoretical dimensions of ethical climate and they are self-interest, company profit, efficiency, friendship, team-interest, social responsibility, personal morality, rules and standard operating procedures and laws and professional codes. Ethical climate is the perception of what constitutes the right behaviour. Ethical climate influences both decision-making and subsequent behaviour in response to ethical dilemmas (Martin and Cullen, 2006). The concept of ethical climate is a powerful and according to Sims (1992) as cited in Laratta (2008) where by the ethical climate of an organization is the shared set of identifications about what correct behaviour is and how ethical issues will be handled. This climate sets the tone for decision making at all levels and in all circumstances. In their paper, Abdullah, 
Sulong and Said (2014) used the term ethical climate interchangeably with the ethical culture. Ethical climate/culture measurement is implemented from the scale developed by Victor \& Cullen (1988) and Suar \& Khuntia (2004). This is based on ten-item that measures management perception on ethical climate in the present organization. This research used the ethical climate questionnaire (ECQ) developed by Victor and Cullen (1998).

\section{Level of Ethics and Integrity}

Ethics and integrity are very important in the organization to prevent a significant harm for the organization, its stakeholders, and society (Asfahani M.A.,2017) Thus, the importance of ethics and integrity should be emphasized so that unethical behaviour can be reduced in the organization. Previous studies have measured level of ethics and integrity in an organisation differently, for example corporate integrity can be measured by means of existence of code of conduct, the quality of compliance programs and the frequency of unethical conduct (Kaptein and Avelino, 2005). According to Barnard, Schurink and De Beer (2008), the two most prominent aspects of integrity are the moral compass and the inner drive. Their analysis indicates that integrity consists of a set of values and principles that act as the norms and standards which govern one's decisions and actions. Barnard et al. (2008) define the moral compass as having and living according to a core set of values and principles. Integrity is ultimately determined by the contextual nature of the moral compass and behaviour where integrity is driven by one's willingness to act according to the internalized values, beliefs, norms and principles that constitute one's moral compass. Barnard et al. (2008) found that integrity points to core values and universally accepted principles.

According to Kaptein (2008), ethical organisational culture can be nurtured through ethical virtues. Virtue ethics is based on the ideas of Plato and Aristotle and Solomon (1999, 2000, 2004) who have applied the virtue theory in an organisational context. According to them, both individuals and organisations should have certain features or virtues, which will enable morally right behaviour. For an organisation to become ethical, these features need to be nurtured in organisational practices. Corporate integrity can also be measured by means of existence of code of conduct, the quality of compliance programs and the frequency of unethical conduct (Kaptein and Avelino, 2005). According to Barnard, Schurink and De Beer (2008), the two most prominent aspects of integrity are the moral compass and the inner drive. Their analysis indicates that integrity consists of a set of values and principles that act as the norms and standards which govern one's decisions and actions. Barnard et al. (2008) define the moral compass as having and living according to a core set of values and principles. Integrity is ultimately determined by the contextual nature of the moral compass and behaviour where integrity is driven by one's willingness to act according to the internalized values, beliefs, norms and principles that constitute one's moral compass. Barnard et al. (2008) found that integrity points to core values and universally accepted principles.

Malaysia have implemented adequate level of Corporate Integrity System or ethical guideline that reflect a situation where organization is less likely to fall as a victim to corruption, damage of reputation and loss of business or opportunities. As cited in Ismail (2013), The Malaysia's National Integrity Plan (NIP) has also identified corporate governance as one of the main elements concerning integrity to the government and private sector. Meanwhile, Corporate Integrity Assessment Questionnaire (CIAQ) is a tool introduced and made available by the Malaysian Institute of Integrity (IIM) to measure the level of corporate integrity in late 2010. Thus, organizations will be using CIAQ as a tool to assess the improvement in making a transparent assurance to ethics and integrity in the workplace. As shown in studies by Rosli et al. (2015) have used these twelve dimensions of corporate integrity system. According to Said and Omar (2014) using the Corporate Integrity System questionnaire (CIAQ) studies on two giant government-linked companies shows that finding found that the level of ethics and integrity on the average is $50 \%$. Company A's level of ethics and integrity is $67.7 \%$ (Utility Company) which is higher than Company B's level of ethics and integrity of 59.7\% (Healthcare Company). Company A scored higher than Company B in terms of Vision and Goals, Legal Compliance, Policies and Rules and Corporate Social Responsibility. The score for Corporate Social Responsibility is highest for both companies however, for infrastructure both companies had lowest score. Infrastructure is the way that organization structures, organizes its ethics and integrity function so that it can convey out its goals effectively. The lowest score shows that these two leading Government Link Company (GLCs) placed less emphasis on integrity infrastructure to support the companies to convey out its integrity's goals effectively (Said \& Omar, 2014).

Relationship between Quality of CIO (Independence, Competence, Work Performance) and Ethical Climate to Level of Ethics and Integrity

Quality of $\mathrm{ClO}$

To further examine this area, this study examines the existence of quality of Chief Integrity Officer (CIO) that might influence the level of ethics and integrity in the public sector Malaysia. Meanwhile, based on Hunt and Vitell's Theory of Ethics (1986), itis more positive rather than normative approach (Torres, 2001). In other research by Zakaria, Haron, and Ismail (2010), they cited that Hunt and Vitell's (1986) theory of ethics states that personal characteristic influences perceived ethical problems, which in turn influences the formation of ethical judgement. Therefore, using this theory best solves the problem and to find out the level of ethics and integrity in public sector organizations. Malaysians need to attain the most beneficial outcome. As cited in Chandler (2015), the existence of the Ethics and Compliance Officer (ECO) position represents the enactment of values in relation to ethical behaviour (Weaver et al., 1999a). This means that through resource commitments, what is the implementation and the response of stakeholders to these commitments. This is important because, in order to remain relevant, institutions must be actively maintained (Dacin, Munir, \& Tracey, 2010; Lok \& de Rond, 2013). It is believed that the contacts that the employees have with their ECO via helpline are a direct 
reflection of the ECO's ability to generate an "ethical culture," which is connected to the ethical behaviour of its employees. Therefore, based on the previous studies the hypotheses as follows:

H1: There is a significant relationship between Quality of chief integrity officer with the level of ethics and integrity.

Independence of this studies is supporting the view of audit committee contributes positively to ethical reporting relation between audit committee independence, which unethical reporting without interference from other parties. Blue Ribbon Committee (1999) state that audit committee independence is positively related to the number of its outside directors who have no personal or financial relations with the firm or its executives. Chandler (2015) cited that ECO implementation captures both the scale and scope of organizational resource commitments to the ECO position. Access to both tangible and intangible resources is understood by management researchers to be a source of power and legitimacy within the firm (Cyert \& March, 1963). Besides that, Abbott et al. (2004) and Persons (2005) find a negative association between the audit committee independence and the probability of financial reporting restatement and financial reporting fraud. Therefore, based on the previous studies the hypotheses as follows:

H1a: There is a significant relationship between independence of the chief integrity officer with the level of ethics and integrity.

Nabila (2008) found that competence have significant relationship with organizational commitment. Zahariah, et al., (2009), Sethela and Rosli (2011), Mujeeb, et al (2011), Selma (2011), Simpson (2012), which indicated that there is a direct and indirect relationship between competence (ability), motivation and organizational culture on organizational commitment. Ulrich (1998), stated that the success of organizations will not be achieved if commitment without competence is not implemented to maintain a sustainable in the organization. Hsiang Wu (2010), the analysis result that competency training was positively related to organizational commitment. Competence plays significant relationship with ethic and integrity in a few significant ethical judgment models by Hunt \& Vitell Theory of Ethics, (1986). According to Hunt \& Vitell, competence influence ethicalness on organizations. Therefore, based on the previous studies the hypotheses as follows:

H1b: There is a significant relationship between competence of the chief integrity officer with the level of ethics and integrity.

Studies (Koopmans et al., 2011) found that work performance is a behavior or action that is relevant to the organization. Whereby, the dimension of work performance that comprise namely task performance which are work quantity and quality, job skills and knowledge and context performance which are showing responsibility, communicating effectively, job-scope and cooperating with others. These two elements have a relationship with the outcome of good performance towards the goal of the organization. Meanwhile, Qun (2013) stated that, a relationship on work performance might affect the internal audit and its efficiency. The significant relationship shows that the quality of work performance which are planned, performed, reviewed and suitability of audit is vital to ensure the objective is accomplished and engaged effectively and efficiently in the organization. Therefore, based on the previous studies the hypotheses as follows:

H1b: There is a significant relationship between competence of the chief integrity officer with the level of ethics and integrity.

\section{Ethical Climate}

Meanwhile, organizational ethical climate refers to a few models of ethical judgment support that has a significant relationship with perceived ethical problem. Hunt and Vitell's Theory of Ethics (1986) also posit that organizational environment influences people in perceiving ethical problems. Similarly, prior studies indicate that the more ethical the employees perceived the climate in their organization, the higher their ability to perceive ethical problems (Marta, 1999; Patterson 1994). Hence, the less likely an unethical judgment can occur. In addition, Shafer (2015) studies the ethical climate of professional accountants in Hong Kong and results shows that an ethical climate has a significant relationship with ethical judgements in the organizations. This result is in line with his previous which examines on local and international CPA firms in China (Shafer, 2008). It looks that there is a significant relationship between perceived ethical climate and intention to conduct questionable actions (Haron, Ismail, \& Na, 2015). Haron et al. (2015) found that the level of perceived ethical climate has a positive effect on the ethical conclusions made. This result is also consistent with the findings of Ghazali and Ismail (2013) whereby the accountants who are attached to corporations with higher ethical standards are stricter in making results in questionable ethical conduct. Therefore, based on the previous studies the hypotheses as follows:

H2: There is a significant relationship between ethical climate with the level of ethics and integrity.

All the above relationships mentioned above can be related with the level of ethics and integrity in the organization. In other words, the quality of CIO namely independence, competence, work performance and ethical climate of the organization influences the ethical decision making and eventually gives impact on the level of ethics and integrity. 


\section{Theoretical Framework}

Figure 2 show the Theoretical Framework; this study utilizes the principle of Hunt and Vitell's Theory of Ethics (1986). As stated in the theory, personal characteristics and environment of organization influence perceived level of ethics and integrity. Following this theory, this study posits that Quality of CIO and ethical climate has significant relationship with level of ethics and integrity in the organizations.

Independents Variable

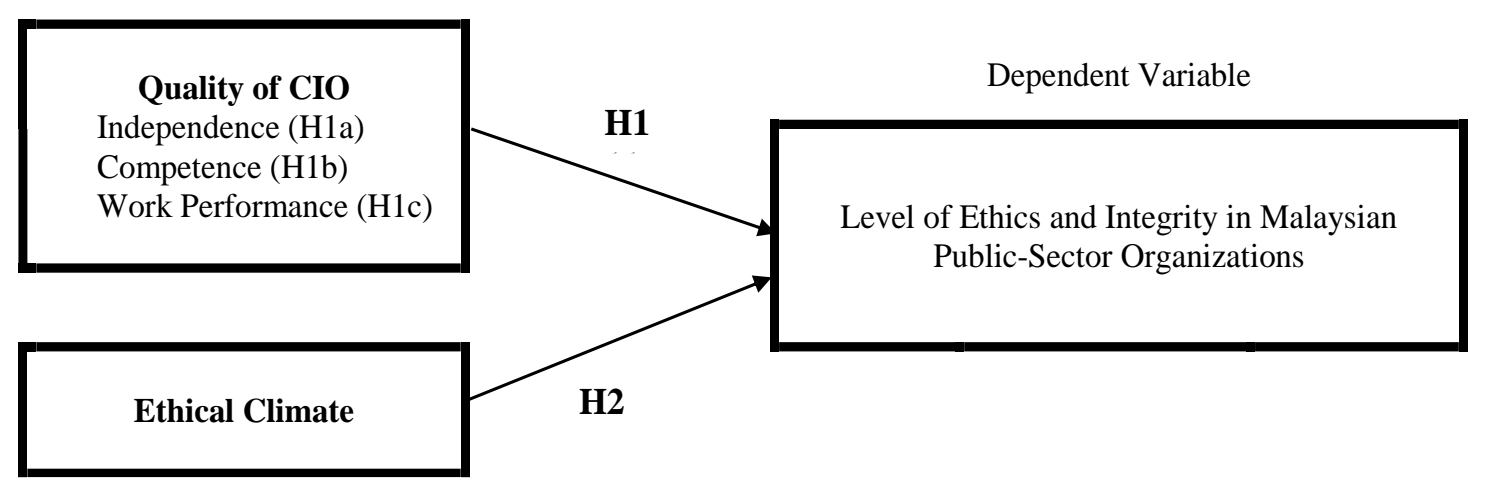

Figure 2: Theoretical framework

\section{METHODOLOGY}

\section{Research Design}

The research design of this study is exploratory research. Exploratory research helps to determine the best research design, data collection methods and selection of subjects. This research was also analysed with the help of statistical tools to find answer for the research questions.

\section{Population and sampling technique}

The population of this research is 128 officers in charge of ethics and integrity in their organisation. It is confined to the Federal Government as it has moderate to high level of risk as compared to the State Government which has a low risk. The names of CIOs have been provided to the researcher by the Corporate Integrity Development Centre (CIDC) and all 128 officers have completed in taking the training modules offered by CIDC of MACC as of August 2017. The total of 128 officers include CIOs, compliance officer, assistance director, investigation officer, secretariat department, director of integrity unit, senior compliance, governance and integrity centre. By using 4 variables and the Sekaran's rule of thumb. To calculate the sample size, 4 variables and the Sekaran's rule of thumb were used. Sample size of 40 to 50 officers would be enough for this study. This study used the sampling method that selected 128 officers of CIO who have been attending the $\mathrm{CeIO}$ programme at federal territory were included.

\section{Measurement of variable}

Quality of CIO will use measurement of independents, competence and work performance as factor influences the level of ethics and integrity in public sector organization.

Independence is based on the level of functional reporting and administrative reporting (Qun, 2013). Whereby CIO should report functionally to the General Secretary of Ministry with a score of "5", score "4" for Ministry, score " 3 " for Chief Executive Officer, score " 2 " to Head of Department and score " 1 " to other bodies in the organization. However, independence of CIO in administrative reporting which is the daily reporting to the Head of Department is important and should be done.

Competence of Chief Integrity Officer is measured based on the sum of mean educational qualification level with experience. Whereby, educational score of " 4 " was for $\mathrm{PhD}$, " 3 " for master, "2" for degree and "1" for diploma. For experience on average, the further experienced staff usually have accumulated more knowledge and skills, whereby the score was " 6 " for more than 15 years, "5" for " 12 to less than 15 years", four for "9 to less than 12 years", three for " 6 to less than 9 years", two for " 3 to less than 6 years" and one for "Less than 3 years". The mean of experience is derived by dividing the sum of score by the maximum score (Qun, 2013).

Work performance, CIO must identify, analyse, evaluate, and record sufficient information to achieve the engagement's objectives. Also, had better identify sufficient, consistent, relevant, and useful information to use in analysing and evaluating the engagement before drawing conclusion and engagement in making a decision (Qun, 2013, IIAM 2008). Thus, measurement work performance of CIO is self-developed based on the roles Certified Integrity Officer in Circular No. 12009 and Series 1, No. 1 2011. The CIO has 10 roles and they are. 1) Coordinate and monitor integrity 
program, 2) Report any breach integrity, 3) Coordinate the actions taken on breach of integrity, 4) Implement the recovery program on integrity 5) Publication of integrity related article, 6) Assist and support of Committee on Integrity, 7) Advice management on integrity matters, 8) Monitor the system services delivery system, 9) Act as a liaison Officer organization to corporate and 10) Ensuring compliance to directive /regulations issued by organization. The respondent is required to rate the level of agreement from scale 1 (strongly disagree) to scale 5 (strongly agree) which shows the measurement items for work performance of CIO.

\section{Ethical Climate}

Measurement of Ethical climate of this study based on Ethical Climate Questionnaire (ECQ) developed by Victor and Cullen (1987, 1988) and further confirmed by Cullen and Bronson (1993). There are nine dimensions to measure the ethical climate and they are employee-focused climate, community-focused climate, obedience to authority, code implementation, self-interest climate, efficiency climate rules and procedures climate, personal ethics climate and law and professional climates. Respondents are required to indicate the degree of agreement using a 5-point Likert scaleranging from 1 (strongly disagree) to 5 (strongly agree). In this study, ethical climate is treated as unidimensional regardless of the dimension based on concept through (Jaramillo et al., 2006; Schwepker, 2001).

\section{Level of Ethics and Integrity}

Dependent variables of this study are level of ethics and integrity. This variable is measured by 12 dimensions (See Appendix 1) of CISM developed by Institute of Integrity Malaysia with total of 208 items statements. It is adapted from Dubinsky and Richter (2008-2009). Global Ethics and Integrity Benchmarks as Figure 3. These benchmarks reflect emerging successful organizational practices. The respondents are required to rate the statements on a five-Likert scale with "0" Not Sure; "1" Strongly Disagree; "2" Disagree; "3" Agree and "4" Strongly Agree. Mean and frequency will be used in explaining the data during the analysis. Meanwhile, Descriptive of CISM 12 Categories Items for Level of Ethics and Integrity : Refer Appendix 1.

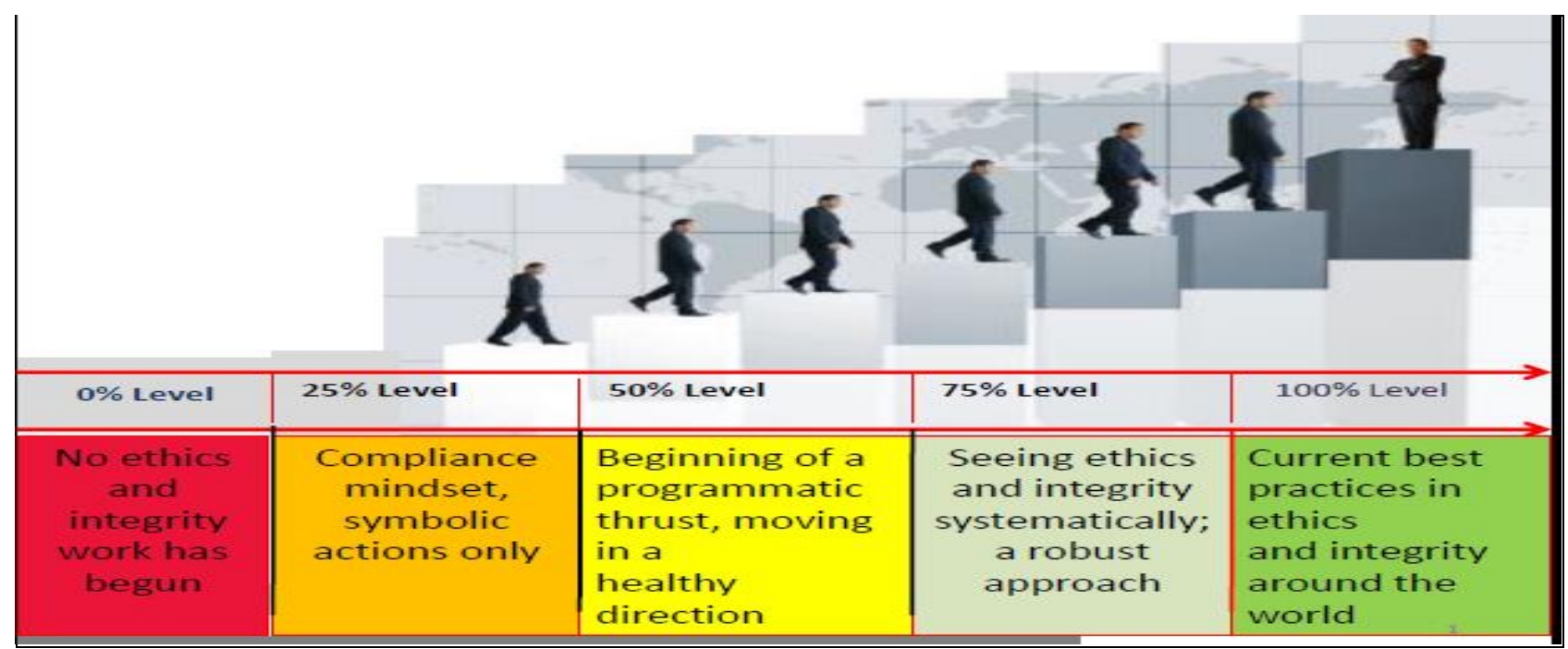

Figure 3: Five Ethics and Integrity Benchmarks Level of CISM

Source: Malaysian Institute of Integrity (IIM)

\section{RESULTS}

A total of 128 online questionnaires (Google form) were emailed to the Chief Integrity Officer (CIO) and the officers of Integrity Unit (IU) in the Malaysian public sector organization at the federal territory. Details of respondents such as name, contact number, address, position and email address were obtained from the Agency Integrity Management Division (BPIA) of Malaysian Anti Corporation Commission (MACC) on August 2017. Data was collected within three months period starting from the second week of August 2017 until the end of October 2017. Eighty-three (83) officers responded to the survey; which made up $65 \%$ rate of response. Summary of the response rate is illustrated in Table 5. Profile of respondents is discussed in the next section.

Table 5: Summary of Response Rates

\begin{tabular}{lc}
\hline Details & Total \\
\hline Questionnaires mailed & 128 \\
Questionnaire answered & 83 \\
Rate of Response (83/128)*100 & $65 \%$ \\
\hline
\end{tabular}


Table 6 indicates the personal detail of the respondent such as gender, race, religion and the level of education. The results showed that more than half whereby,53 respondents $(63.9 \%)$ were male while remaining 30 respondents $(36.1 \%)$ were female. The respondents were represented by four racial compositions that were Malay (91.6\%), Chinese (2.4\%), Indians (3.6\%) and others (2.4\% including Siamese and Orang Asli). Most of the respondents were Muslims (95 2\%), followed by Buddhism (2.4\%) and Christians (1.2\%). Most of the respondents (43.3\%) were in the age range of 35 to 44 years old, followed by 45 to 55 years old (22.9\%), 25 to 34 years old (18.1\%) and the least 55 years old and above (15.7\%). Almost half of the respondents possess a bachelor's degree (49.4\%), followed by master's degree $(39.8 \%)$, diploma $(8.4 \%)$ and others $(2.4 \%)$.

For the working place type of organization consists of seven department namely Jabatan Kemajuan Orang Asli, Jabatan Hal Ehwal Khas (Unit Integriti), Jabatan Perangkaan Malaysia, Jabatan Bantuan Guaman, Jabatan Wakaf Dan Haji, Jabatan Pertanian Semenanjung Malaysia and Jabatan Taman Laut Malaysia. The existence of integrity unit for any breach of ethics and integrity in the past five years, whether the respondent is the head of the integrity unit or not. The next category inquires more details on the respondent's related matter with the integrity unit which include full designation of respondents, either they obtain any professional certificate or qualification related to ethics and integrity program. Their working experience related to ethics and integrity portfolio, the operational and functional reporting level as well as the existence of other officers' responsibility for managing the ethics and integrity programme independently are important.

Table 6: Summary of Profile Respondents

\begin{tabular}{llcc}
\hline Demographic & Characteristic & $\begin{array}{c}\text { Frequency } \\
(\mathrm{N}: 83)\end{array}$ & $\begin{array}{c}\text { Percentage } \\
(\%)\end{array}$ \\
\hline Gender & Male & 53 & 63.9 \\
& Female & 30 & 36.1 \\
\hline Race & Malay & 76 & 91.6 \\
& Chinese & 2 & 2.4 \\
& Indian & 3 & 3.6 \\
& Others & 2.4 \\
\hline Religion & Muslim & 95.2 \\
& Buddhism & 1.2 \\
& Christianity & 1 & 1.2 \\
& Others & 1 & 2.4 \\
\hline Age & 25-34 Years & 18.1 \\
& 35-44 Years & 15 & 43.3 \\
& $45-54$ Years & 36 & 22.9 \\
& 55 and above & 19 & 15.7 \\
\hline Highest Qualification & Master & 13 & 39.8 \\
& Degree & 33 & 49.4
\end{tabular}

In the descriptive statistics of the principal construct, the mean was applied as a measure of central tendency, which showed that all variables were above their midpoint level (Sekaran, 2003). Table 7 shows the summary of descriptive statistics for all independent variables. The highest mean of 4.21 is recorded by work performance (one of the Quality of chief integrity officer dimensions) with standard deviation (SD) of 0.79 , followed by ethical climate (mean value 4.10 , SD 0.32). This indicates that the respondents strongly agree with all items regarding the work performance and ethical climate in the organisation.

Table 7: Summary of Descriptive Statistics for Independent Variables

\begin{tabular}{ccccc}
\hline Item & Min & Max & Std. Deviation & Mean \\
\hline Work Performance & 1.67 & 5.00 & .79 & 4.20 \\
Ethical Climate & 3.33 & 4.83 & .32 & 4.10 \\
\hline
\end{tabular}

Table 8 shows the descriptive statistics for dependent variable such as level of ethics and integrity which comprises of twelve dimensions. Overall, it shows that the mean score of the twelve components range from 3.30 to 4.20, indicating that respondents rated the items in each dimension as above average or at least scale 3 (neutral). Meanwhile, the standard deviation of the twelve dimensions range from 0.37 to 0.75 , which shows not much of a variation between the 
respondents' answer. Out of the twelve components, infrastructure showed the lowest score with a mean of 3.30 and standard deviation of 0.37 , indicating that the respondents view the way organization organizes ethics and integrity on function structure, staff, resources, formal or informal reporting as average. Dimension of legal compliance, policies and rules scored the highest mean of 4.20 with standard deviation of 0.56 , indicating that the respondents agree the organizations that adopted laws, policies, rules and guidance, ethics and integrity system with the best practices in the organization.

Table 8: Summary of Descriptive Statistics for 12 Dimensions of Ethics and Integrity

\begin{tabular}{lccccc}
\hline Item & Items & Min & Max & Std. Deviation & Mean \\
\hline Legal Compliance, Policies and Rules & 14 & 3.00 & 5.00 & .56 & 4.20 \\
Disciplinary Measure and Rewards & 11 & 2.55 & 5.00 & .63 & 4.11 \\
Vision and Goals & 12 & 3.00 & 4.75 & .47 & 4.08 \\
Leadership & 14 & 1.93 & 5.00 & .68 & 4.07 \\
Accountability & 5 & 3.00 & 5.00 & .64 & 4.05 \\
Whistleblowing & 9 & 2.78 & 5.00 & .67 & 4.04 \\
Organizational Structure & 12 & 2.58 & 5.00 & .61 & 4.04 \\
Ethics Communications & 14 & 2.21 & 5.00 & .72 & 4.04 \\
Confidential Advices and Support & 8 & 2.75 & 5.00 & .68 & 3.92 \\
Ethics Training and Education & 9 & 1.33 & 5.00 & .75 & 3.87 \\
Measurements, Research and Assessment & 11 & 2.09 & 5.00 & .70 & 3.86 \\
Infrastructure & 5 & 2.40 & 4.20 & .37 & 3.30 \\
\hline
\end{tabular}

Overall Mean: 47.58/12 = $3.97(79.30 \%)$

Table 9 illustrates each of the independent variables included in the model contributed deeper to the prediction of the dependent variable. This was done by analysing the Coefficients output for hypotheses study. The largest beta coefficient is 0.32 was scored by work performance (WP). This means that this variable makes the strongest unique contribution in explaining the level of ethics and integrity, whereby the variance explained by all other variables in the model is controlled. The Beta value for ethical climate (EC) was slightly lower 0.27, indicating that it made less of a unique contribution.

Table 9: Summary of Hypotheses Testing of Coefficients (Relationship between Independence, Competence, Work Performance and Ethical Climate with the Level of Ethics and Integrity)

\begin{tabular}{|c|c|c|c|c|c|c|c|c|c|}
\hline \multirow{2}{*}{ Нyро } & \multirow{2}{*}{$\begin{array}{c}\text { Independent } \\
\text { Variables }\end{array}$} & \multicolumn{2}{|c|}{$\begin{array}{c}\text { Unstandardized } \\
\text { Coefficients }\end{array}$} & \multirow{2}{*}{$\begin{array}{c}\text { Standardized } \\
\text { Coefficient }\end{array}$} & \multirow{2}{*}{ t-value } & \multirow{2}{*}{ Sig. } & \multicolumn{2}{|c|}{$\begin{array}{c}\text { Collinearity } \\
\text { Statistics }\end{array}$} & \multirow{2}{*}{ Decision } \\
\hline & & Beta & $\begin{array}{l}\text { Std. } \\
\text { Error }\end{array}$ & & & & Tolerance & VIF & \\
\hline & (Constant) & .973 & & & 1.486 & .141 & & 5.089 & \\
\hline $\mathrm{H} 1 \mathrm{a}$ & Independence & .233 & .655 & .095 & .941 & .350 & -0.43 & 1.444 & $\begin{array}{c}\text { Not } \\
\text { Significant }\end{array}$ \\
\hline $\mathrm{H} 1 \mathrm{~b}$ & Competence & .456 & .248 & .162 & 1.684 & $.096 * *$ & -0.65 & 2.291 & Significant \\
\hline $\mathrm{H} 1 \mathrm{c}$ & Work Perform & .204 & .066 & .315 & 3.093 & $.003^{*}$ & 0.01 & 0.711 & Significant \\
\hline $\mathrm{H} 2$ & Ethical Climate & .426 & .167 & .270 & 2.577 & $.012 *$ & 0.15 & 1.550 & Significant \\
\hline
\end{tabular}

Dependent Variable: Level of Ethics and Integrity

Significant: $(\mathrm{P}<0.05)^{*}$ and $(\mathrm{P}<0.10)^{* *}$

Table 10 presents the crosstabulations and chi-square test results of the quality of CIO against position as head of Integrity Unit. It can be seen that there is a significant quality of CIO with position as head integrity unit in the organizations. It is shown that being a head of integrity unit has resulted in a higher score of the quality of chief integrity officer $32(60.4 \%)$ compared to not being the head of integrity. 
Table 10: Result of Cross Tabulation and Chi-Square Test between organizational commitment against gender (Male and Female)

\begin{tabular}{lcccc}
\hline \multirow{2}{*}{ Crosstab } & & \multicolumn{3}{c}{ Gender } \\
\cline { 3 - 5 } Organizational & & Male & Female & Total \\
\hline \multirow{2}{*}{ Commitment } & Lower & 24 & 21 & 45 \\
& Higher & 29 & 30 & 38 \\
\cline { 2 - 5 } & Total & 53 & Asymp. Sig (2-side) \\
\hline Chi-Square Test & Value & Df & .030 \\
Person Chi Square & 4.715 & 1 & .028 \\
Likelihood Ratio & & 1 & .031 \\
Liner by Linear & 4.818 & 1 & \\
N. of Valid Cases & 4.658 & & \\
\hline
\end{tabular}

Significant $(\mathrm{p}<0.05)$

\section{DISCUSSION}

One of the purposes of this study is to examine the level of ethics and integrity in the Malaysian public sector. Descriptive statistics have shown the overall score of level of ethics and integrity is $79.30 \%$. At this level, it can be seen that the Malaysian public sector is at the level of "seeing ethics and integrity systematically and having a robust approach" in the organization. This shows that the Malaysian public sector is serious in promoting ethics and integrity to avoid unethical issues in the organization. Meanwhile, amongst the twelve dimensions of level ethics and integrity, the highest score is achieved by the legal compliance, policies, and rules dimension (84\%), which indicates that the public sectors are doing well in its effort to put in place the internal framework that provides guidance for ethical behaviour. In other words, the core laws, policies, rules and guidance that comprise the legal framework for' ethics and integrity system, are in place. It shows that the public sector organization implements compliance with the external legal framework within the organizations' operation. This indicates that the organization's code of conduct specifies the mutual rights, duties, and obligations of both the organizations and its employees.

Essentially, the organization has translated its legal commitments into concrete actionable guidance that is enforceable in the public sector. The second highest score is disciplinary and reward measures which indicate that the organization has explicit disciplinary action for wrongdoing or misconduct as well as an explicit system to reward ethical action. Vision and goals ranked number three in terms of its contribution to the level of ethics and integrity of the organization. It shows that the public sector is aware that having upholding core ethical values are important for their organizations. However, ethics and integrity is currently, neither recognized nor discussed seriously. Integrity should not be limited to legal compliance or the organization's formal internal rules structure only, but integrity should be embedded into the for organization's and individual's performance or key performance indicator. Thus, initiatives should be taken by the organization to incorporate the ethics and integrity in the organisation's vision and goals.

A slightly higher score of leadership dimension $(81.40 \%)$ was seen. This shows that the leaders in the public sector organizations take responsibility to shape, guide, and support the organization's ethics and integrity initiatives. However, from the results found, it can be seen that there is little or no active leadership, involvement, or accountability regarding ethics and integrity. However, it can be seen that most of the leaders receive training and coaching in integrity and provide coaching about integrity to their subordinates. A lot of improvement should be done for the accountability dimension to increase the level of ethics and integrity in the organizations. One of the improvements that can be made, is the disclosure of financial performance of the organisation to the stakeholders. The organization should react or respond to audit/inquiry officer seriously and must disclose information required. The organizations should also use ICT and other social media to disclose the relevant information to the stakeholders.

Whistleblowing is the sixth place in terms of score $(80.80 \%)$. It shows that the organization supports employees to speak up and make reports of unethical actions. The strategies and assurances are being offered to people who wish to make the organization mindful of conceivable deceptive conduct, offense or any illicit activities. To achieve the $100 \%$ level, the organizations should focus in making the policy that encourage employees to follow the "chain of command" when facing workplace issues. The next dimension is organizational culture with the same score as the whistleblowing dimension. Organizational culture explores the efforts by the organizations in shaping the organizations' culture (both written and unwritten rules that dictate how work is performed and goals are reached) and whether that culture actively promotes ethical conduct. Results show that the respondents think that "it is considered safe to speak about wrongdoings at the organization". However, it would be better if there are role models among the leaders in the organization. Findings show that most of the employees tend to keep a low profile in the organization and they perceived a significant gap between the organization's ethical communication and its actions.

The ethics communication dimension reveals the same score as whistleblowing and organizational culture dimensions, which are also ranked at number six. This indicates that the public sector organizations have implemented all three dimensions (ethics communication, whistleblowing and organizational culture) to maintain the level of ethics 
and integrity in their organizations. Thus, ethics communication is important to act as reminders to employees to behave ethically. Employees should be reminded of the organisation's vision and goals, and also given information on unethical behaviour that occurs in the organisation. Also, communicating ethical conduct and integrity is an important aspect to promote the reputation of the organization. In addition, occasional reminders by the human resource department or management to employees, about policies and compliance requirements is necessary to increase the level of ethics in the public sector organization.

Confidential advice and support dimension (78.40\%) showed that in general, the organization provides confidential, neutral, professional and independent ethics advice to employees, supervisors, managers, executives, members of the governing bodies and other stakeholders. Almost all respondents agree that there is special resource available for those who seek ethics advice confidentially. It is believed that ethics advice is confidential, and employees are encouraged to speak directly to their leaders if they have questions about ethics, integrity or compliance. The organization's chief legal officer (whom in this study is proxied to the chief integrity officer) is not really being viewed as the ultimate source for the best ethical advice. The integrity officer is also not being fully authorized to issue "safe harbour" letters in which the employees, who are seeking for advice, can be reassured that they cannot be disciplined because they relied upon that advice. Thus, the organizations should improve on these issues if the highest percentage score is to be achieved for this confidential advice and support dimension.

The next dimension of ethics training and education obtains a slightly lower score and ranks in the bottom three This dimension explores the ethics and integrity awareness, skill-building training and education, and the integration of such training into the overall development to all staff. The respondents opined that the person in charge of designing and delivering training does have specific expertise in ethics and integrity. It's because the training programs on ethics and integrity are not brief and focus on informing the employees about policies and meeting legal requirements. The training provided is not being fully integrated with the overall training curriculum, but, being offered as a stand-alone course. Thus, organizations should provide a minimum number of state-of-the-art integrity training per year to all board members, executives, managers, supervisors, staffs and agents, and establish a minimum number of ethics training hours to be completed annually for each category of learner.

The second-lowest score is measurement, research and assessment dimension with a score of 77.20\%. However, it still provides an indication that the organization does undertake research to support ethics strategies to create the culture of ethics and integrity. Organizations need to continuously try to improve their level of ethics and integrity by benchmarking with other organisations who have successfully measured and assessed the level of ethics of their organisation.

The lowest in twelve dimensions is infrastructure, in which the public sector should focus on this dimension to increase the level of ethics and integrity. Respondents agreed that organization should have an infrastructure or individual responsible for integrity in their organization. The result also indicates that majority of the respondents acknowledge that organizational integrity is recognized as a unique discipline requiring specialized skills, knowledge, and experience and the integrity functions should not be performed as an additional, secondary duty of mid-level staff. The integrity function should be subjected to regular audit oversight.

Meanwhile, for the three dimensions to measure the Quality of Chief Integrity Officer, it shows that Independence was found not to have significant relationship with the level of ethics and integrity. This result is consistent with Qun (2013) where he found that independence was not significant in determining the internal audit effectiveness. In this study, independence was also found not significant in determining the level of ethics and integrity. This implies that the reporting level used as the proxy of the independence dimension does not affect the quality of Chief Integrity Officer. In addition to that, it was found that both operational and functional reporting level in this current study was to their head of department. One of the possible reasons is because, unlike previous studies, this study focused on the public sector entities where the culture of reporting is directly referred to the immediate superior for any issues that raised.

The second dimension of the quality of chief integrity officer (CIO) was competence. It was found to have significant and positive relationship with the level of ethics and integrity in the Malaysian public sector organizations studied in this research. Competence in this study refers to the working experience and the level of education. The finding in this study is in line with the previous research by Irwin and Bradshaw (2011). They also found that the more competence officer will influence a good ethics programs to be in place. Hunt and Vintel (1986,) had also discussed the significant of competence in some ethical judgement models explained in their Theory of Ethics. Indirectly, previous research conducted by Mihret and Yismaw (2007), Rai (2008) and Qun (2013) had found that the competency of the personnel is crucial factor in determining the overall quality of their expert field. These researchers agreed upon the finding on which competence internal auditors are required to ensure they performed their audit works properly and at highest quality. Similarly, if the officers in this current study possess the competency such as work experience related to ethics and integrity, the skills and knowledge regarding the ethics and integrity, it is most likely that they will contribute in the overall quality of Chief Integrity Officer which subsequently influence the level of ethics and integrity in the organization. For instance, the competency level of CIO in this study is quite high where almost $90 \%$ of the respondents have either master's degree or a bachelor's degree qualification with $42 \%$ of the respondents have average year of services related to ethics and integrity for more than 12 years. Moreover, more than $80 \%$ of respondents own professional certificate or qualification related to ethics and integrity program. These had contributed to the high percentage score level of ethics and integrity obtained in this study. Hence, it can be concluded that the concern of engaging the right person with suitable skills especially the Chief Integrity Officer would be portrayed through the improvement on the level of ethics and integrity in their respective organizations. This can also be supported by recent quotes in the local online newspaper 
stating that the certified integrity officers during their five-year service, had taken down 4,000 complaints and pursued to the end 1,600 of the complaints including those classified as "misconduct" (News Strait Times, 2018).

The dimension of Quality of CIO, work performance has the highest mean score of 4.21, indicating that respondents mostly agreed with the job description of the chief integrity officer. Work performance also scored the largest beta coefficients (0.32) in the multiple regression analysis indicating that this dimension has the strongest contribution in explaining the variance of the level of ethics and integrity. This finding is in line with the research paper published by Treviño et al. (2014) where they found that the efforts of ethics and compliance officer to initiate and manage variety of ethics and integrity related programs can be beneficial in terms of improving employees' perceptions and decreasing inappropriate conduct. The work performance as the dimension of the personnel's quality is also supported by the previous research conducted by Qun (2013). He found that the work performance of the internal auditors contributes to the overall quality of internal auditors. Respondents perceived that they are responsible to coordinate and monitor the ethics and integrity programme as well as implementing a recovery integrity program, monitoring the services delivery system in the organization, and assisting the Integrity and Governance Committee. Moreover, they are also in charge of coordinating the actions taken on the breach of ethics and integrity. Integrating all these work scope responsibilities, it ensures the quality of chief integrity officer and eventually contributes in the higher percentage score level of ethics and integrity as discussed in the previous section.

Moreover, integrity units should be established with its own head of integrity unit. It can be seen from chi-square result that there is significant relationship between the position as head of integrity unit with the quality of chief integrity officer. Even though it is not empirically proven in this research that establishment of integrity unit is highly interrelated with the work performance of the CIO, realistically, people work properly well if they have specific job description and scope of work as compared to those who are not given any specific job description. In this study, work performance is measured based on the CIO's role to coordinate and monitor integrity program, report any breach of integrity, coordinate the action take on breach of integrity, implement the recovery program on integrity to increase the level ethics and integrity in public sector.

Ethical climate was found to have significant and positive relationship with the level of ethics and integrity (Beta coefficient 0.27 ; $<0.05$; confidence interval 95\%). This is supported by the Hunt and Vitell's Theory of Ethics (1986,) where apart from personal characteristics which is, he quality of CIO, the organizational environment also plays crucial factors in influencing the level of ethics and integrity in the organization. In this study, this organizational environment is represented by the ethical climate. In other words, ethical climate of the organization may influence the ethical decision and attitude or behaviour making which eventually gives impact to the level of ethics and integrity. This finding is also consistent with research conducted by Chouaib and Zaddem (2013) which suggested that the ethical climate have an impact on the effectiveness trust of work and consequently, increase the level of ethics and integrity within the organization. Ethical climate was also found to be a critical factor in influencing the employees' perception of how their organization emphasizes the ethical aspect of business and encourages employees ethical work behaviours (Kwon et al., 2013). Similarly, Shafer (2015) analysed the ethical climate of professional accountants in Hong Kong and reported that there is a significant relationship with ethical judgement on an organization. The mean score obtained for this variable is also quite high which is 4.09. The high mean value indicates that the respondents perceived their organization practices a high ethical climate in public sector. This study also found that the public sector organizations promote a transparent ethical surrounding, implements a strict code of ethical rules and enforces mechanism to prevent unethical behaviour. These are essential factors in creating an awareness of ethical and integrity among public servants. 


\section{CONCLUSION}

Thus, the contributions made by this study is useful for raising awareness especially among the public employee to adopt good governance in various ways to ensure the organization is more influenced by an ethics and integrity environment in the public sector. Thus, an office of integrity should be set up with full authority to implement ethical activities. The organizations in the ministry department and statutory body, can be headed by a Chief Integrity Officer with sufficient funding given to carry out their duties and promote and disseminate on ethics and integrity. And, through competence which are through experience and education level and work performance which is the job scope of quality of CIO become significant to increase level of ethics and integrity in the public sector. CIO with these attributes will contribute insights and can help to improve the integrity unit in the organizations so that the level of ethics and integrity can be increased higher and consequently, reduce the unethical scandals in the organization.; The competence level of the CIO is measured based on their experience and level of education. With regards to that, by appointing a highly experienced and skilled CIO, it could help in solving the unethical scandal effectively. To increase the competency level of the CIO, they are highly advised to enroll in more professional qualification courses related to ethics and integrity. All CIO should have graduated with the Certified Integrity Officer course provided by the Malaysian Anti-Commission Academy (MACA). The government can also improve the existing ethical climate by implementing the control and monitoring procedure of the employee at various departments of public sector to enhance the ethical behavioural practices. This is Iso that, employees at public sector are expected to perform high integrity and high ethical values consistently during the undertaking of their tasks with transparency and responsibility. Other than that, top management should look at the procedure, code of conduct, legislation, and guideline as these plays a major role in influencing level of ethics and integrity in public sector organisations. Despite many efforts taken to increase the level of integrity, the number of complaints and the number of arrested people remain high. To create the culture and climate of integrity, the civil servants are encouraged to participate in seminars on integrity, forums, and dialogues organized by relevant agencies and organizations. Besides that, these initiatives are concurrently strengthened with compliance constructs such as the national pillars (Rukun Negara), code of ethics, integrity pledge, general circulars and many other formal documents expounding good values. The limitations and suggestion of this study for future research on similar topic to make an improvement in this study field. Firstly, the number of samples should be increased and could be focused on the Chief Integrity Officers who has graduated the Certified Integrity Officer course conducted by Malaysian Anti-Corruption Academy, in other words the future study focuses on CeIO (Chief Integrity Officers). Therefore, the effectiveness of those in charge of integrity, whom has gone through the certification process can be examined. Furthermore, the sample studied can be extended to include the ethics officers from the State Government and a comparison can be made between the ethics officers at the Federal Government. A future research may also include an analysis of gender and the focuses on the integrity unit in public sector organizations all over Malaysia for both states departments and government link agencies along with the federal departments. Interviews can also be done to enable more in-depth explanation of issues studied. Moreover, on the issue of the distribution of questionnaire, the researcher should deliver it personally to the respondents personally, so that the researcher may take the opportunity to conduct a briefing session on explaining the questionnaire to the respondent rather than using online questionnaire. By doing so, this could avoid any potential conflict or misunderstanding among the respondents. In addition to that, the number of questionnaires for respondent needs to be reduced and the analyzed by using PLS-SEM. It is strongly suggested that the research approach could possibly be utilized by a qualitative research approach such as an in-depth interview with the Chief Integrity Officers with case studies approaches in combination with survey questionnaires.

\section{ACKNOWLEDGEMENT}

A special thanks is dedicated to all research group members, Institute of Integrity Auditor Malaysia (IIM), Mrs. Rasidah Binti Abdul Karim who is the Head of Corporate Integrity Development Centre in the Malaysian Anti-Corruption Academy (MACA), Mr Alan Kirupakaran who is the Governance Officer of Minister in the Prime Minister's Department, Institute of Internal Auditor Malaysia (IIAM), National Audit Department (NAD) of Malaysia and associate members of FIM's Governance and Integrity Centre (FGIC). The usual disclaimer applies. This research was supported in part by a grant from the University of Malaysia Pahang.

\section{REFERENCES}

Accounting Research Institute (2016). Corruption Risk and Mitigation Approaches in Public and Private Sector. Retrieved on 26 August from http://ari.uitm.edu.my/main/index.php/hicoe-research-cluster/corporate-integrity-ethics-andrisk-management

Abbott, L.J., Parker, S. and Peters, G. (2004), “Audit committee characteristics and restatements”, Auditing: A Journal of Practice \& Theory, Vol. 23 No. 1, pp. 69-87.

Ali, E. I. E. (2015). Public sector accounting and financial management in Malaysia. Malaysia: Unpublished First Draf

Aliza Shah (2018, July 16). [Exclusive] 28 Integrity Officers to be reinstated. New Strait Times. Retrieved: from://https://www.nst.com.my/news/exclusive/2018/07/391197/exclusive-28-integrity-officers-be-reinstated 
Azleen, L., \& Nurul, N.Z. (2013). Factor Affecting The Computerised Account System (CAS) Usage in The Public Sector. Journal of Internet Banking and Commerce, JIBC April 2013, Vol. 18, No. 1. Retreive Internet Journal: http://www.arraydev.com/commerce/jibc).

Asfahami, M., A (2017). The Importance of Organizational Ethics and its Barriers. Retrieved: https://www.linkedin.com/pulse/importance-organizational-ethics-barriers-ahmed-m-asfahani-ph-d

Baker, J., Mapes, J., New, C. \& Szwejczewski, M. 1997. A hierarchical model of business competence. Integrated Manufacturing Systems Vol. 8 No. 5/1997, 265- 272

Barnard, A., Schurink, W., \& De Beer, M. (2008). A conceptual framework of integrity. SA , 34, 40-49

Bartels, L.K., Harrick, E., Martell, K. and Strickland, D. (1998), "The relationship between ethical climate and ethical problems within human resource management”, Journal of Business Ethics, Vol. 17 No. 7, pp. 799-804

Blue Ribbon Committee (1999), "Report and recommendations of the Blue Ribbon Committee on improving the effectiveness of corporate audit committees", The Business Lawyer, Vol. 54 No. 3, pp. 1067-1095

Buller, P.F. and McEvoy, G.M. (1999), "Creating and sustaining ethical capability in the multi-national corporation”, Journal of World Business, Vol. 34 No. 4, pp. 326-343

Camerer, M.I. (2006). Measuring public integrity. Journal of Democracy, 17 (1), 152-165

Chandler, D. (2015). Institutions and Ideals: Philip Selznick's Legacy for Organizational Studies. Research in the Sociology of Organizations, 44, 149-174. https://doi.org/10.1108/S0733-558X201544

Chen, Z.-X., \& Tan, K. H. (2011). The perceived impact of JIT implementation on operations performance: Evidence from Chinese firms. Journal of Advances in Management Research, 8(2), 213-235. doi: 10.1108/09727981111175957

Chouaib, A \& Zaddem, F., (2013). The Climate at Work. Retreived: researchgate.net/publication/276387544_The Ethical Climate at Work

Circular No.1 Year (2009) and Series 1 No. 1Year (2011) - Directive YAB Prime Minister: Gerakan Pemantapan Keutuhan Sistem Pengurusan Pentadbiran Kerajaan Malaysia, Pelaksanaan Program Pegawai Integriti Bertauliah

Corporate Intgrity System Malaysia (CISM) Official Website. The Journey. Retrieved from http://www.cism.my/aboutcism/journey, 2016

Corruption Perception Index, Transparency International (TI) (2017). Retrieved on 13 February, http;//www,transparency.org/news/feature/corruption_perception_index_2016,

Cyert, R. and March, J. (1963). The Behavioural Theory of the Firm. Englewood Cliffs, NJ: Prentice Hall

Dacin, M. T., Munir, K., \& Tracey, P. (2010). Formal dining at Cambridge colleges: Linking ritual performance and institutional maintenance. Academy of Management Journal, 53(6), 13931418.

Dubinsky, J. E., \& Richter, A. (2008). Global Ethics and Integrity Benchmark. US

Dubsinky, J. E., \& Richter, A. (2009). Global Ethics and Integrity Benchmark US

Erpenbeck, J. and Michel, L.P. (2006), “Competency-based quality securing of e-learning (CQ-E)”, in Ehlers, U.-D. and Pawlowski, J.M. (Eds), Handbook on Quality and Standardisation in E-Learning, Springer, Berlin and Heidelberg, pp. 125-141.

Frey, A. and Ruppert, J.-J. (2013), "Structuring and detecting competence”, in Beck, K. and Zlatkin-Troitschanskaia, O. (Eds), From Diagnostics to Learning Success, Sense, Rotterdam, pp. 185-198

Governance Integrity Anti-Corruption Centre (GIACC). (2019). National Anti-Corruption Plan (NACP) 2019 - 2023. Retrieved from http://integriti.my/giacc/wp-content/uploads/2019/01/National-Anti-Corruption-Plan-20192023.pdf

Ghazali, N.A.M., \& Ismail, S. (2013). The influence of personal attributes and organizational ethics position on accountants' judgment: Malaysian scenario. Social Responsibility Journal, 9(2), 281-297

Haron, H., Ismail, I., \& Na, A. Lo. (2015). The Effect of Moral Reasoning, Exposure to Ethics and Perceived Ethical Climate on Ethical Judgement of Auditors in Malaysia, 8(2), 25-66

Heinen, T. (2011), Planung der soziotechnischen Wandlungsfähigkeit in Fabriken, PZH, Garbsen

Hunt, S.D., \& Vitell, S.J., (1993). A General Theory of Marketing Ethics: A Retrospective and Revision. In Ethics in Marketing ,pp.775-784, (N.C. Smith \& J.A.Quelch (Ed)

Hunt, S.D., \& Vitell, S.J. (1986). A general theory of marketing ethics. Journal of Macromarketing, 6(1), 5-16

Hunt, S.D., Wood, V.R. and Chonko, L.B. (1989), "Corporate ethical values and organizational commitment in marketing”, Journal of Marketing, Vol. 53 No. 3, pp. 79-90. 
Hunt, S.D., \& Vitell, S.J., (1993). A General Theory of Marketing Ethics: A Retrospective and Revision. In Ethics in Marketing ,pp.775-784, (N.C. Smith \& J.A.Quelch (Ed)

Institute of Internal Auditors (IIAM). (2008), The International Professional Practices Framework

Irwin, J., \& Bradshaw, K. (2011). The ethics challenge: establish an ethics ambassador network to help embed an ethical culture. Strategic HR Review, 10(4), 26-32. Retrieved://doi. org /10.1108/14754391111140972

Jaramillo, F., Mulki, J.P. and Solomon, P. (2006), “The role of ethical climate on salesperson's role stress, job attitudes, turnover intention, and job performance”, Journal of Personal Selling \& Sales Management, Vol. 26 No. 3, pp. 271-282.

Kaptein, M. (2008). Developing and testing a measure for the ethical culture of organizations: The corporate ethical virtues model. Journal of Organizational Behavior, 29, 923-947.

Kamaliah, Marjuni, Mohamed, Mohd-Sanusi \& Anugerah, 2018 (Effectiveness of monitoring mechanisms and mitigstions of fraud incidents in the public sector, 2018

Kauffeld, S. (2006), "Self-directed work groups and team competence", Journal of Occupational and Organizational Psychology, Vol. 79 No. 1, pp. 1-21

Kolthoff, E., Erakovich, R., \& Lasthuizen, K. (2010). Comparative analysis of ethical leadership and ethical culture in local government: The USA, The Netherlands, Montenegro and Serbia. International Journal of Public Sector Management, 23(7), 596-612. https://doi.org/10.1108/09513551011078879

Koopmans, L., Bernaards, C. M., Hildebrandt, V. H., Schaufeli, W. B., de Vet Henrica, C. W., \& van der Beek, A. J. (2011). Conceptual Frameworks of Individual Work Performance. Journal of Occupational and Environmental Medicine, 53(8), 856-866. https://doi.org/10.1097/JOM.0b013e318226a763

Kwon Choi, B., Koo Moon, H., \& Ko, W. (2013). An organization's ethical climate, innovation, and performance. Management Decision, 51(6), 1250-1275. https://doi.org/10.1108/MD-Sep-2011-0334

Laratta, R. (2008). Ethical Climate in Nonprofit and Government Sectors : A Comparative Study between Japan and UK

Young, (2004), 1-14. https://doi.org/10.1080/14719037.2010.501620

Lok, J., \& de Rond, M. (2013). On the plasticity of institutions: Containing and restoring practice breakdowns at the Cambridge University boat club. Academy of Management Journal, 56(1), 185207

Lokman. A \& Talib T. A, (2015). The Public of Administrators. Conference: The 5th International Conference on Public Policy \& Social Science, At Seremban Malaysia

Malaymail (2017, March 01. Public Sector Governance: Filling The Gap - Latifah Merican Cheong. Malaymail. Retrieved from https://www.malaymail.com/

Martin, K.D. and Cullen, J.B. (2006), "Continuities and extensions of ethical climate theory: a meta-analytic review", Journal of Business Ethics, Vol. 69 No. 2, pp. 175-194

Marta, J.K.M. (1999), “An empirical investigation into significant factors of moral reasoning and their influences on ethical judgment and intentions", doctoral dissertation, Old Dominion University, Norfolk, VA (UMI No: 9928703), available at: www.proquest.umi.com.html (accessed May 24, 2006).

Matsui, Y. (2007). An empirical analysis of just-in-time production in Japanese manufacturing companies. International Journal of Production Economics, 108(1-2), 153-164. doi: 10.1016/j.ijpe.2006.12.035

Meyer, G., Brünig, B., \& Nyhuis, P. (2015). Employee competences in manufacturing companies - an expert survey. 34(8), 1004-1018. https://doi.org/10.1108/JMD-06-2014-0056

Mujeeb Ehtesham, Tahir Masood Muhammad, Shakil Ahmad Muhammad. 2011. Relationship between Organizational Culture and Performance Management Practices: A Case of University in Pakistan. Journal of Competitiveness. Issue 4/2011, pp. 78-86

Nabila, A. A. (2008). The relationship between Psychological Empowerment and organizational Commitment: A case study among employees in construction sector in Kota Kinabalu, Sabah. School of Business and Economic, UMS

Nawanir, G., Lim, K. T., \& Othman, S. N. (2013). Impact of lean practices on operations performance and business performance: some evidence from Indonesian manufacturing companies. Journal of Manufacturing Technology Management, 24(7), 1019-1050. doi: 10.1108/JMTM-03-2012-0027

NKRA E-Newletter (2013). Certified Integrity Officer Programme (CeIO) Enculturing integrity and ethics at the work place.

Patterson, D.M. (1994), “A model of ethical/unethical decision making by auditors in the big-six accounting firms", doctoral dissertation, Georgia State University, Atlanta, GA, available at: www.proquest.umi.com (accessed April 21, 2005)

Persons, O. S. (2005) The relation between the new corporate governance rules and the likelihood of financial statement fraud. Review of Accounting \& Finance, 4(2), 125-148 
Pimental, J. R. C., Kuntz, J.R.., \& Elenkov, D. S. (2010). Ethical decision-making an integrative model for business practices. European Business Review, 22 (4), 359 - 376.

Qun, T. C. (2013). Internal audit quality, audit committee quality, symbiotic relationship between audit committee and internal audit effectiveness.

Rauner, F., Heinemann, L., Maurer, A., Haasler, B., Erdwien, B. and Martens, T. (2013), "Measuring professional competence", in Rauner, F., Heinemann, L., Maurer, A. and Haasler, B. (Eds), Competence Development and Assessment in TVET (COMET), Springer Science + Business Media, Dordrecht, pp. 1-17.

Russell, R. S., \& Taylor, B. W. (2014). Operations management and supply chain management (8th ed.). Singapore: John Willey \& Sons, Inc.

Said, J., Alam, M. M., \& Khalid, M. A. (2015). Relationship between good governance and integrity system: empirical study on the public sector of Malaysia. Humanomics, 32(2), 354-371. https://doi.org/10.1108/H-04-2014-0037

Schminke, M., Arnaud, A. and Kuenzi, M. (2007), “The power of ethical work climates”, Organizational Dynamics, Vol. 36 No. 2, pp. 171-186

Selma, Altindis. (2011). Job motivation and organizational commitment among the health professionals. African Journal of Business Management. Vol. 5(21), pp. 8601-8609,

Sethela June and Rosli Mahmood. 2011. The Relationship between Role Ambiguity, Competency and PersonJob Fit With the Job Performance of Employees in the Service Sector SMEs in Malaysia. Journal Business Management Dynamics. Vol.1, No.2, August 2011, pp.79-98

Shafer, W.E. (2008). Ethical climate in Chinese CPA firms. Accounting, Organizations and Society, 33(7-8), 825-835.

Shafer, W.E. (2015). Ethical climate, social responsibility, and earnings management. Journal of Business Ethics. 126(1), 43-60.

Siddiquee, N. A. (2010). Combating corruption and managing integrity in Malaysia: A critical overview of recent strategies and initiatives. Public Organization Review, 10(2), 153-171. https://doi.org/10.1007/s11115-0090102-y

Sims, R.R. (1992), "The challenge of ethical behavior in organizations", Journal of Business Ethics, Vol. 11 pp.505-13

Schwepker C.H. Jr. (2001). "Ethical Climate's Relationship to Job Satisfaction, Organizational Commitment, and Turnover Intention in the Salesforce", Journal of Business Research, 54 (1), 39-52.

Torres, M.B., (2001). Character and Decision-Making. Doctoral dissertation, University of Navarra, Canada. Retreived April, 10, 2015 from http://www.proquest.umi.com

Treviño, L. K., den Nieuwenboer, N. A., Kreiner, G. E., \& Bishop, D. G. (2014). Legitimating the legitimate: A grounded theory study of legitimacy work among Ethics and Compliance Officers. Organizational Behavior and Human Decision Processes, 123(2), 186-205. Retrived from: https://doi.org/10.1016/j.obhdp.2013.10.009

Ulrich, Dave, R. 1998. Intellectual Capital = Competence x Commitment. Sloan Management Review. Vol. 39 p. $15-26$.

Viswesvaran, C., \& Ones, D. S. (2000). Perspectives on models of job performance. International Journal of Selection and Assessment, 8(4), 216-226.

Weaver, G. R., Treviño, L. K., \& Cochran, P. L. (1999a). Corporate ethics programs as control systems: Influences of executive commitment and environmental factors. Academy of Management Journal, 42(1), 4157. Weaver, G. R., Treviño, L. K., \& Cochran, P. L

Zahariah Mohd Zain, Razanita Ishak, Erlane K Ghani. (2009). The Influence of Corporate Culture on Organizational Commitment. European Journal of Economics, Finance and Administrative Sciences. ISSN 1450-2275 Issue 17 pp. 16-26.

Zakaria, M., Haron, H., \& Ismail, I, (2010). Knowledge of ethics, perceived ethical problem and ethical judgement. Journal of Financial Reporting and Accounting, 8 (1), 50-64, https://doi.org/10.1108/IJBM-07-2013-0069 